\title{
Estudio preliminar de la diversidad genética en procedencias de Sabal mexicana de Nicaragua aplicando marcadores moleculares
}

Domingo Guido ${ }^{1}$ y Verónica Díaz ${ }^{2}$

1. Tesista de la Universidad Nacional Autónoma de Nicaragua (UNAN-León)

2. Docente-Investigador de la Universidad Nacional Autónoma de Nicaragua (UNAN-León).

Recibido: julio 2006 / aceptado: octubre 2006

PARA EVALUAR DE FORMA PRELIMINAR LA VARIABILIDAD GENÉTICA de 12 procedencias de Sabal mexicana Mart. en el Occidente de Nicaragua, se aplicó la técnica Random Amplified Polymorphic DNA (RAPD). De las 42 bandas generadas por seis cebadores en una muestra de 44 individuos, 92.8\% resultaron polimórficas. El mayor polimorfismo lo presentaron las procedencias en las cuales se analizó un mayor número de muestras (5), destacándose El Limonal (82.78\%) y Santa Rosa (78.82\%). El agrupamiento de las muestras en un dendrograma refleja alta diversidad genética entre ellas ( $25 \%$ de similitud). La mayoría de las muestras se ubican independientemente de la procedencia a la que pertenecen y de su localización geográfica, lo que puede ser debido principalmente al pequeño número de muestras (máximo 5) por procedencia, aunque también puede ser el resultado del pequeño número de cebadores (6) y a que, probablemente, la mayor diferencia genética se encuentre dentro y no entre las procedencias.

Palabras clave: genética-Nicaragua-evaluación / polimorfismo (zoología).

\section{Introducción}

La palma de techo (Sabal mexicana Mart.) es una planta no maderable que, desde tiempos inmemoriales, ha estado asociada a la actividad antropogénica, mediante el uso de sus hojas para techar construcciones y casas rurales (Ramos y Quezada, 1980). Actualmente representa un recurso económico importante especialmente para muchas familias nicaragüenses que la utilizan en el mercado artesanal, y en el sector turístico 
para el techado de ranchos rústicos (Armas y Canales, 2003), además del valor ornamental y paisajístico de la especie.

Durante años, las poblaciones de S. mexicana han sufrido serias perturbaciones ocasionadas por actividades como el incremento de la industria turística, avance de la frontera agrícola, etc., lo que ha provocado la rápida destrucción de las poblaciones de esta especie. Las consecuencias ecológicas de estas perturbaciones son evidentes; sin embargo, la pérdida y reducción de su diversidad genética deben evaluarse ya que puede tener graves consecuencias para la sobrevivencia de la especie. Se ha comprobado que, en muchas especies, la pérdida o baja diversidad genética, se relaciona con la reducción en su capacidad de reproducción y sobrevivencia (fitness reproductivo). Además, es precisamente la diversidad genética la que confiere a las poblaciones el potencial para evolucionar y adaptarse a los cada vez más acelerados cambios ambientales (Frankham y col., 2002).

Dada la creciente demanda de este recurso, es necesario realizar actividades de conservación y recuperación de palmares para un uso sostenible de la especie. Para ello, se requiere, entre otras acciones, detectar y estimar la diversidad genética presente en las diferentes poblaciones. La importancia del estudio sobre los niveles y distribución de la diversidad genética en poblaciones naturales para diseñar eficaces estrategias de conservación y manejo ha sido reconocida por diferentes autores (Hogbin y Peakall, 1999; Hamrick, 1994; González y Sosa, 2002); y por instituciones internacionales como el Programa de Medio Ambiente de las Naciones Unidas (PNUMA) y la Unión Internacional para la Conservación de la Naturaleza (UICN), que consideran los recursos genéticos como prioridad en los programas de conservación de la biodiversidad (Frankham y col., 2002).

Desde los años 80, se han desarrollado diferentes técnicas para detectar la variabilidad genética a nivel del ADN basadas en la PCR; entre ellas, RAPD, que se ha utilizado desde el inicio de los años 90 en una serie de estudios de caracterización y evaluación de la diversidad genética de diferentes especies (Soliman y col., 2003, entre otros).

Este trabajo tiene por objetivo realizar un estudio preliminar de la diversidad genética de 12 procedencias de palma (Sabal mexicana Mart.) de los departamentos de León, Chinandega y Masaya de Nicaragua, para determinar el nivel de diversidad genética (polimorfismo) y establecer el índice de similitud genética en las muestras analizadas. Esta información facilitaría la toma de decisiones acertadas para la conservación, reforestación y manejo de la palma paceña, en beneficio de los productores que disponen de este recurso y de los sectores populares que lo utilizan, haciéndolo sostenible de acuerdo a su demanda y en beneficio del medio ambiente.

\section{Materiales y métodos}

Obtención del material vegetal. El material vegetal (semillas) utilizado en este estudio proviene de 44 individuos pertenecientes a 12 procedencias de los departamentos de León, Chinandega y Masaya (Ilustración 1). Las semillas fueron proporcionadas por el Proyecto "Dinámica Ecológica del Bosque Seco y Fomento del Cultivo de la Palma Paceña (Sabal mexicana Mart) en el Occidente de Nicaragua". Las muestras fueron recolectadas de 
palmares en sitios naturales, considerando una distancia mínima entre plantas de 50 a 100 m (Dávila, 2003).

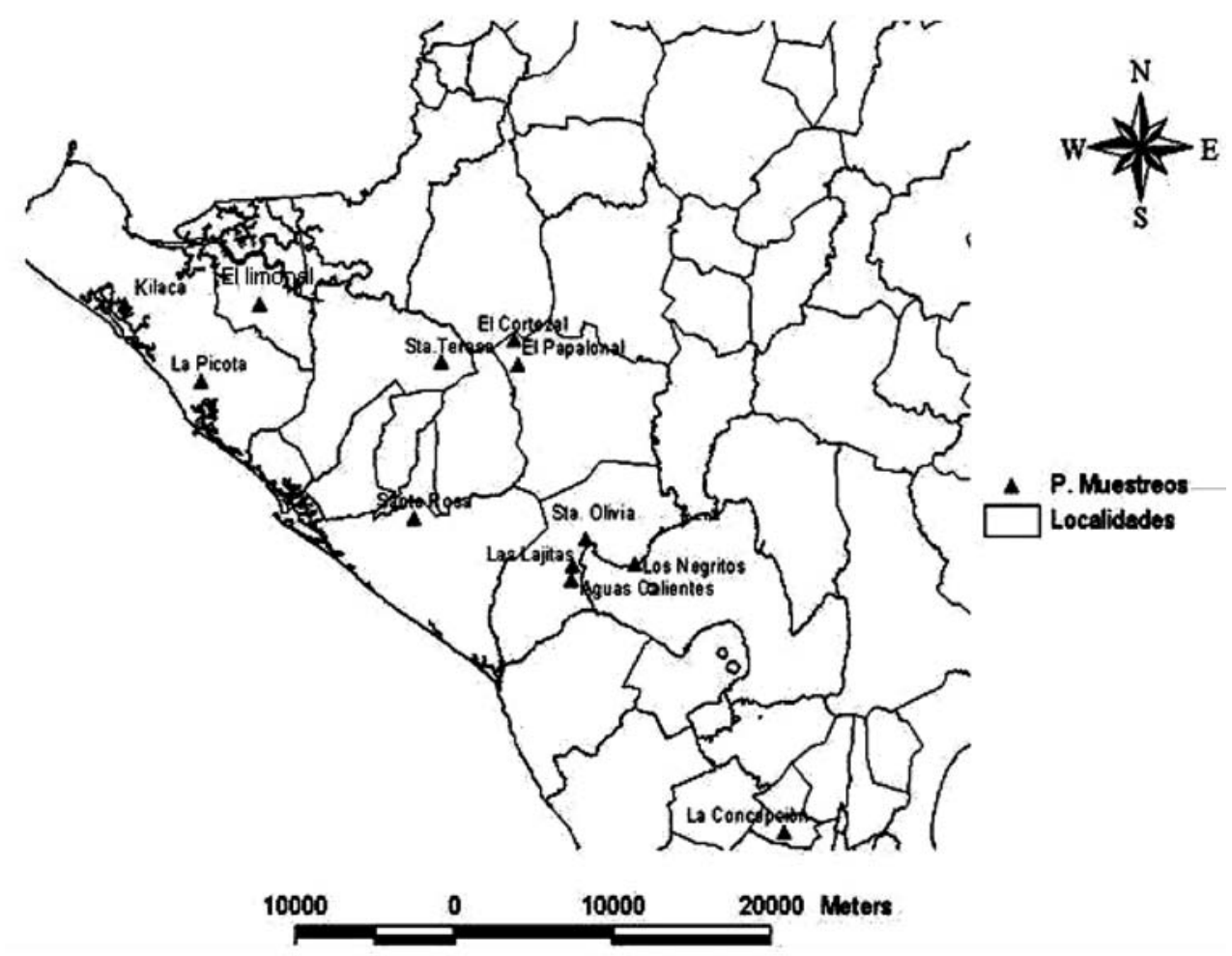

Ilustración 1. Mapa sobre la ubicación geogràfica de las procedencias de Sabal mexicana utilizadas en este estudio (INETER 1998, ArcView 3.2 1996).

Extracción de ADN. Para la extracción del ADN, se utilizó el procedimiento de Möller y col. (1992) con pequeñas modificaciones. El ADN se aisló a partir de un polvo fino obtenido del embrión de cada semilla. El proceso de obtención de ADN se inició con $0.02 \mathrm{~g}$ de tejido, que se incuba inicialmente en un buffer de extracción TES (Tris 100mM, pH=8.00, EDTA 10 $\mathrm{mM}$ y SDS $2 \%)$ en presencia de proteinasa $\mathrm{K}(20 \mathrm{mg} / \mathrm{ml})$ a $60^{\circ} \mathrm{C}$ por 1 hora y posteriormente 10 min con $\mathrm{NaCl} 5 \mathrm{M}$ y CTAB al 10\% para lograr la lisis celular. Para separar los ácidos nucléicos de otros compuestos y restos celulares, el homogenado se trata primeramente con cloroformo-alcohol isoamílico (24:1) y luego, se centrifuga para recuperar el sobrenadante. Los ácidos nucléicos se precipitan en isopropanol a $-20^{\circ} \mathrm{C}$; el sedimento se lava con etanol al 70\%, se deja secar a temperatura ambiente y se resuspende en Buffer TE (Tris 10mM y EDTA 1mM). Para eliminar el ARN, se trata con ARNasa $(10 \mathrm{mg} / \mathrm{ml}) \mathrm{y}$, finalmente, el ADN se conserva a $-20^{\circ} \mathrm{C}$. Se realiza un chequeo del $\mathrm{ADN}$ cualitativo por electroforesis y cuantitativo por espectrofotometría.

Proceso de amplificación por PCR. Las amplificaciones se llevaron a cabo básicamente por el procedimiento descrito por Williams y col., (1990), utilizándose un termociclador (Gene 
Amp PCR System 2700). Las reacciones se llevaron a cabo en un volúmen final de $25 \mu$ l y la mezcla consistió de agua, Buffer de PCR 10X, cebador $0.2 \mu \mathrm{M}$, dNTPs $200 \mu \mathrm{M}, 5 \mathrm{ng} / \mu \mathrm{l}$ de ADN y $1 \mathrm{U}$ de $\mathrm{Taq}$ polimerasa (Sigma). El programa se inició con una desnaturalización a $92^{\circ} \mathrm{C}$ por 3 min seguidas por 45 ciclos de $30 \mathrm{seg}$ a $92^{\circ} \mathrm{C}, 1$ min a $42^{\circ} \mathrm{C}$ y $30 \mathrm{seg}$ a $72^{\circ} \mathrm{C}$ con una extensión final de $8 \mathrm{~min}$ a $72^{\circ} \mathrm{C}$. Los productos de la amplificación se separaron por electroforesis en geles de agarosa al $1.4 \%$ teñidos con bromuro de etidio $(0.5 \mathrm{ug} / \mathrm{ml})$ y fotografiados sobre una lámpara UV.

Selección de cebadores. Se ensayaron 41 cebadores (OPERON) de secuencia arbitraria en tres muestras elegidas al azar, del total de 44 muestras y de ellos se seleccionaron seis que produjeron bandas de mayor intensidad, reproducibles y que detectaban polimorfismo, para analizar el total de las muestras.

Análisis de datos. Con los marcadores obtenidos de la amplificación, se calculó el porcentaje de bandas polimórficas y se realizó un análisis de agrupamiento de las muestras por sus similitudes genéticas con el paquete estadístico NTSYS (Numerical Taxonomy and Multivariate Analysis System) versión 1.5 (Rohlf, 1993).

\section{Resultados y discusión}

Patrones de bandas. Los cebadores que produjeron mayor número de bandas fueron AE-16 y N-12 con 11 y 9 bandas respectivamente, teniendo los restantes cebadores un promedio de 4.7 bandas. Del total de 42 bandas obtenidas, 39 resultaron polimórficas (92.8\%) lo que podría indicarnos la posible cantidad de variabilidad genética presente en estas procedencias.

Los cebadores que generaron mayor polimorfismo en el conjunto de la muestra analizada fueron AE-16 y E-12 (ambos con un 72\%). A partir de la frecuencia de bandas polimórficas, se obtuvo el porcentaje de polimorfismo generado en las 16 procedencias con todos los cebadores y por cebador con cada una de las procedencias (Cuadro 1). Se puede observar que la frecuencia de bandas polimórficas es, por lo general, diferente en cada una de las procedencias con el conjunto de los cebadores, debido posiblemente, a la variabilidad presente dentro de las procedencias como a la diferencias en el tamaño de las muestras de cada procedencia: las procedencias que presentaron mayor porcentaje de polimorfismos fueron las representadas en este estudio con cinco individuos, destacándose entre ellas El Limonal (82.78\%) y Santa Rosa (78.82\%). Sin embargo, la procedencia de Aguas Calientes, a pesar de estar representada sólo por dos individuos, se encuentra entre las que presentaron polimorfismos aproximados al $65 \%$, al igual que las otras tres procedencias con mayor número de muestras analizadas, lo que permite inferir una alta diversidad genética presente en esa procedencia. Con los cebadores utilizados no se obtuvieron bandas que diferenciaran una determinada procedencia, puesto que todas las procedencias compartían las bandas, pero en diferentes frecuencias. 
Cuadro 1. Porcentaje de bandas polimórficas obtenidas con RAPD. Número y porcentaje (de bandas polimórficas obtenidas con cada cebador en cada procedencia analizada, con sus respectivas medias).

\begin{tabular}{|c|c|c|c|c|c|c|c|c|c|}
\hline \multirow{3}{*}{ № } & \multirow{3}{*}{ Muestras } & \multirow{3}{*}{ Procedencia } & \multicolumn{7}{|c|}{ № de Bandas / Cebadores } \\
\hline & & & 4 & 11 & 9 & 5 & 5 & 5 & $=39$ \\
\hline & & & N-09 & AE-16 & $\mathrm{N}-12$ & E-12 & A- 04 & E- 19 & Media \\
\hline 1. & 3 & Las Tejitas & $\begin{array}{c}2 \\
(33.33)\end{array}$ & $\begin{array}{c}7 \\
(63.63)\end{array}$ & $\begin{array}{c}6 \\
(66.66)\end{array}$ & $\begin{array}{c}4 \\
(80)\end{array}$ & $\begin{array}{c}2 \\
(40)\end{array}$ & $\begin{array}{c}2 \\
(33.33)\end{array}$ & $\begin{array}{c}3.83 \\
(52.83)\end{array}$ \\
\hline 2. & 5 & Sta. Rosa & $\begin{array}{c}4 \\
(66.66)\end{array}$ & \begin{tabular}{|c}
9 \\
$(81.81)$
\end{tabular} & $\begin{array}{c}7 \\
(77.77)\end{array}$ & $\begin{array}{c}4 \\
(80)\end{array}$ & $\begin{array}{c}5 \\
(100)\end{array}$ & $\begin{array}{c}4 \\
(66.66)\end{array}$ & \begin{tabular}{|c}
5.5 \\
$(78.82)$
\end{tabular} \\
\hline 3. & 5 & El Limonal & $\begin{array}{c}4 \\
(66.66)\end{array}$ & $\begin{array}{c}11 \\
(100)\end{array}$ & \begin{tabular}{|c}
6 \\
$(66.66)$
\end{tabular} & $\begin{array}{c}4 \\
(80)\end{array}$ & $\begin{array}{c}5 \\
(100)\end{array}$ & $\begin{array}{c}5 \\
(83.33)\end{array}$ & \begin{tabular}{|c|}
5.83 \\
$(82.78)$
\end{tabular} \\
\hline 4. & 5 & La Picota & $\begin{array}{c}3 \\
(50)\end{array}$ & $\begin{array}{c}11 \\
(100)\end{array}$ & $\begin{array}{c}6 \\
(66.66)\end{array}$ & $\begin{array}{c}3 \\
(60)\end{array}$ & $\begin{array}{c}2 \\
(40)\end{array}$ & $\begin{array}{c}4 \\
(66.66)\end{array}$ & $\begin{array}{c}4.83 \\
(63.89)\end{array}$ \\
\hline 5. & 2 & Los Negritos & $\begin{array}{c}3 \\
(50) \\
\end{array}$ & $\begin{array}{c}4 \\
(36.36) \\
\end{array}$ & $\begin{array}{c}5 \\
(55.55) \\
\end{array}$ & $\begin{array}{c}3 \\
(60) \\
\end{array}$ & $\begin{array}{c}2 \\
(40) \\
\end{array}$ & $\begin{array}{c}2 \\
(33.33) \\
\end{array}$ & $\begin{array}{c}3.17 \\
(45.87)\end{array}$ \\
\hline 6. & $\mathbf{5}$ & Sta. Teresa & $\begin{array}{c}3 \\
(50)\end{array}$ & $\begin{array}{c}10 \\
(90.90)\end{array}$ & $\begin{array}{c}9 \\
(100)\end{array}$ & $\begin{array}{c}3 \\
(60)\end{array}$ & $\begin{array}{c}2 \\
(40)\end{array}$ & $\begin{array}{c}3 \\
(50)\end{array}$ & $\begin{array}{c}5 \\
(65.15)\end{array}$ \\
\hline 7. & 5 & Sta. Olivia & $\begin{array}{c}3 \\
(50)\end{array}$ & $\begin{array}{c}8 \\
(72.72)\end{array}$ & $\begin{array}{c}7 \\
(77.77)\end{array}$ & $\begin{array}{c}4 \\
(80)\end{array}$ & $\begin{array}{c}3 \\
(60)\end{array}$ & $\begin{array}{c}3 \\
(50)\end{array}$ & $\begin{array}{c}4.67 \\
(65.42)\end{array}$ \\
\hline 8. & 2 & Aguas Calientes & \begin{tabular}{|c}
2 \\
$(33.33)$ \\
\end{tabular} & $\begin{array}{c}7 \\
(63.63) \\
\end{array}$ & $\begin{array}{c}8 \\
(88.88)\end{array}$ & $\begin{array}{c}5 \\
(100)\end{array}$ & $\begin{array}{c}2 \\
(40)\end{array}$ & $\begin{array}{c}4 \\
(66.66)\end{array}$ & $\begin{array}{c}4.67 \\
(65.42)\end{array}$ \\
\hline 9. & 4 & Kilaca & $\begin{array}{c}3 \\
(50) \\
\end{array}$ & $\begin{array}{c}9 \\
(81.81) \\
\end{array}$ & \begin{tabular}{|c}
6 \\
$(66.66)$ \\
\end{tabular} & $\begin{array}{c}3 \\
(60) \\
\end{array}$ & $\begin{array}{c}3 \\
(60) \\
\end{array}$ & $\begin{array}{c}3 \\
(50) \\
\end{array}$ & $\begin{array}{c}4.5 \\
(61.75) \\
\end{array}$ \\
\hline 10. & 4 & El Papalonal & $\begin{array}{c}3 \\
(50)\end{array}$ & $\begin{array}{c}8 \\
(72.72)\end{array}$ & $\begin{array}{c}5 \\
(55.55)\end{array}$ & $\begin{array}{c}4 \\
(80)\end{array}$ & $\begin{array}{c}2 \\
(40)\end{array}$ & $\begin{array}{c}4 \\
(66.66)\end{array}$ & \begin{tabular}{|c|}
4.33 \\
$(60.82)$
\end{tabular} \\
\hline 11. & 2 & El Cortezal & $\begin{array}{c}3 \\
(50) \\
\end{array}$ & $\begin{array}{c}3 \\
(27.27) \\
\end{array}$ & $\begin{array}{c}4 \\
(44.44) \\
\end{array}$ & $\begin{array}{c}1 \\
(20) \\
\end{array}$ & $\begin{array}{c}3 \\
(60) \\
\end{array}$ & $\begin{array}{c}4 \\
(66.66) \\
\end{array}$ & $\begin{array}{c}3 \\
(44.73) \\
\end{array}$ \\
\hline 12. & 2 & La Concepción & $\begin{array}{c}3 \\
(50) \\
\end{array}$ & $\begin{array}{c}8 \\
(72.72) \\
\end{array}$ & $\begin{array}{c}4 \\
(44.44) \\
\end{array}$ & $\begin{array}{c}5 \\
(100) \\
\end{array}$ & $\begin{array}{c}2 \\
(40) \\
\end{array}$ & $\begin{array}{c}3 \\
(50) \\
\end{array}$ & $\begin{array}{c}4.17 \\
(59.53)\end{array}$ \\
\hline & & Media & $\begin{array}{c}3 \\
(50) \\
\end{array}$ & $\begin{array}{l}7.92 \\
(72) \\
\end{array}$ & $\begin{array}{c}6.1 \\
(68) \\
\end{array}$ & $\begin{array}{l}3.58 \\
(72) \\
\end{array}$ & $\begin{array}{l}2.75 \\
(55)\end{array}$ & $\begin{array}{c}3.42 \\
(54.16) \\
\end{array}$ & \\
\hline
\end{tabular}

Agrupamientos de procedencias de acuerdo a su similitud genética. En el análisis de agrupamiento de acuerdo a la similitud genética, obtenida a partir del método de análisis UPGMA (Unweighted Pair Group Method Average), (Ilustración 2), todas las muestras se relacionan con un bajo porcentaje de similitud genética (25\%) lo que significa que hay una alta diversidad genética entre ellas (75\%). Las muestras se ubican en un total de ocho grupos principales, indistintamente de su procedencia y se disgregan a través del dendrograma, aunque pertenezcan a una misma procedencia, se puede observar una ligera 
tendencia a agruparse por procedencia en las muestras de El Limonal y Santa Olivia. Por lo tanto, tampoco se puede inferir alguna relación entre los agrupamientos generados y las localizaciones geográficas de las distintas procedencias.

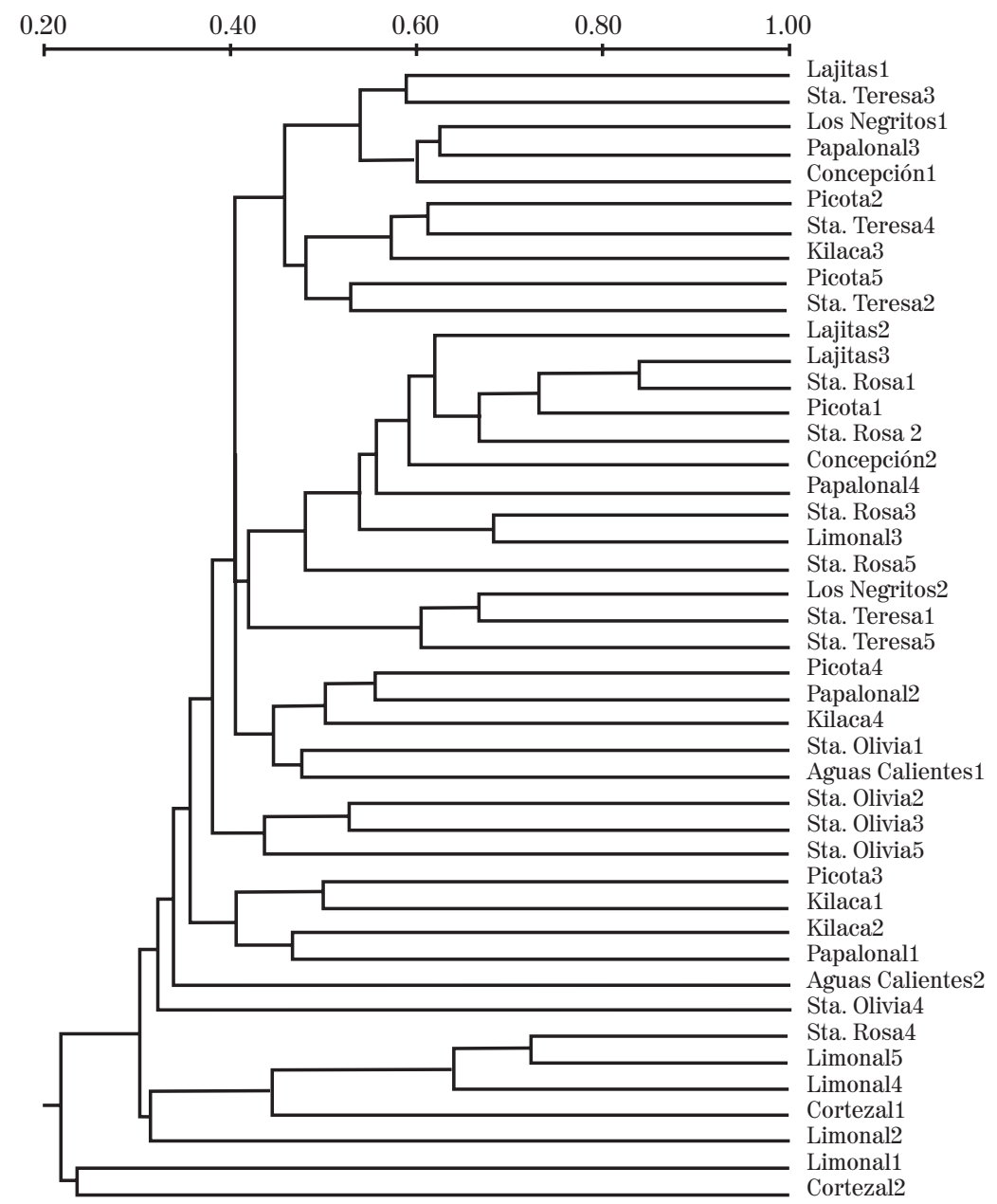

Ilustración 2. Dendograma obtenido con el método de agrupamiento UPGMA, a partir de las distancias genéticas de Sabal mexicana Mart en las 12 procedencias analizadas.

Estos resultados se deben, probablemente a diversos factores. El primero y principal, es el pequeño número de muestras analizadas por procedencia: el máximo es de cinco en El Limonal, Santa Olivia, Santa Rosa, Santa Teresa y La Picota. El número de muestras en estudios para determinar diversidad genética en poblaciones naturales, generalmente se efectúa con poblaciones de más de cien individuos, con un promedio entre 15 y 20 individuos por procedencia o poblaciones (ejemplo, Bartish y col., 2000); en estudios con menor número de muestras, de seis a 13 por población, representan más del 50\% del total de números de plantas por población (Nebauer y col. 1999). En otros trabajos consultados, el que presenta el menor número de muestras por población es de cinco en Gliricidia sepium aplicando la PCR (Dawson y col., 1995) y en Vitellaria paradoxa (Fontaine y col., 2004), número que es 
el máximo de muestras en el estudio de la palma, pero sólo en cinco procedencias, por lo que constituye un estudio preliminar.

En un trabajo reportado por Nybom y Bartish (2000), se concluye que, a pesar de la gran variación en el número de plantas por población (de 10 a 30 plantas), no se encontró ninguna asociación entre el parámetro No. de muestras con los parámetros de diversidad. En ese estudio, el menor número de muestras es de 10. Otro autor, Bussell (1999) no encontró cambios en la diversidad genética cuando incrementó el tamaño de las muestras de ocho a 14 y 30 plantas en dos poblaciones de Isotoma petrea. Sin embargo, experimentos de simulación han demostrado que la diversidad entre poblaciones decrece considerablemente de dos a cinco plantas (similar al número de muestras en este estudio de Sabal mexicana), pero se vuelve estable de 10 a 15 plantas (Isabel y col., 1999).

Otro factor que podría influir en estos resultados (pero en mucha menor medida), es que tan sólo se utilizaron seis cebadores que produjeron 39 marcadores polimórficos. Son pocos para tener resultados concluyentes de la extensión y distribución de la diversidad genética en la palma. En el estudio citado de Nybom y Bartish (2000), se reporta que no encontraron asociación entre el número de marcadores y los parámetros genéticos; sin embargo, recomiendan usar al menos de 50 a 100 marcadores polimórficos. Por lo tanto, serían suficientes pocos cebadores cuando éstos generan gran cantidad de marcadores polimórficos. Se reportan varios trabajos realizados con pocos cebadores; entre éstos, uno con tan sólo cinco cebadores (Chalmers y col., 1994) y con seis cebadores (Nebauer y col., 1999). Sin embargo, la mayoría de los trabajos publicados en los que se utiliza RAPD para análisis y estimaciones poblacionales, incluyen un promedio de 10 cebadores: en un estudio en $P$. oocarpa (Díaz y col., 2001) se utilizan 12 cebadores y Fontaine y col., (2004) usaron 15. Un mayor número de cebadores quizás habría generado bandas únicas en determinadas procedencias que permitieran la agrupación por procedencia.

Un tercer factor a considerar en el resultado de este estudio es la posible cantidad de variación genética presente en estas procedencias. Debido a que, en general, el nivel de diversidad genética de las especies depende de muchos factores, incluyendo el tipo de cruzamiento (Gonzáles y Sosa, 2002), se realizó una intensa búsqueda bibliográfica para tratar de determinar el tipo de cruzamiento (autogamia o exogamia) de Sabal mexicana. No se encontró ningún reporte sobre esta información. El Doctor Brunell (2005), del Departamento de Ciencias Biológicas de la Universidad del Pacífico (USA), que está realizando un estudio con esta especie utilizando el marcador AFLP, manifestó que tampoco ha podido obtener esa información.

En general, las plantas autógamas presentan menor diversidad genética que las alógamas debido a una gran influencia de la deriva genética. En este estudio de las 42 bandas generadas por los seis cebadores, 39 son polimórficos en el total de muestras analizadas. Es decir, un $92.8 \%$, lo que indica la gran cantidad de polimorfismo presente en estas procedencias y la efectividad de los marcadores RAPD para detectar variación genética. Con esta técnica, se amplifican principalmente regiones del ADN no codificantes y repetidas que constituyen la mayor parte del genoma de los eucariotas, en las cuales las tasas de sustitución nucleotídica son el doble que en las regiones codificantes (Nei, 1987). 
La distribución de las diferentes muestras de las 12 procedencias en el dendrograma parece indicar que hubiera poca diferenciación entre las distintas procedencias, ya que algunas muy distantes geográficamente se agrupan más cercanamente. Esto podría ser debido a que la mayor variación genética esté dentro de las procedencias más que entre procedencias. Resultados similares se han reportado en diversos estudios utilizando RAPD. Por ejemplo, en la palmera canaria (Phoenix canariensis) con reproducción cruzada, en la que el 75.9\% de la diversidad genética se encuentra dentro de las poblaciones y tan sólo el 24.1\% entre poblaciones (González y Sosa, 2002). En Licuala glabra (Palmae), la partición de la varianza molecular usando AMOVA revela que la mayoría de la varianza total puede ser atribuida a la variación dentro de las poblaciones (68.4\%), comparada con un 31.5\% de diferenciación entre poblaciones (Loo y col., 1999). Resultados similares se obtienen también en otras especies alógamas con diferentes tipos de marcadores. Por ejemplo, con isoenzimas (Hamrick y Godt, 1989). Sin embargo, en este estudio, hay que considerar que experimentos de simulación han demostrado que la diversidad entre poblaciones decrece considerablemente de dos a cinco plantas, como se señaló anteriormente.

Estos resultados preliminares obtenidos en las procedencias de Sabal mexicana, sugieren que esta especie pudiera ser alógama, ya que la reproducción cruzada genera mayor diversidad genética intrapoblacional (González y Soza, 2002). Sin embargo, se requeriría hacer un estudio de polinización manual controlada o con marcadores alozímicos para determinarlo de forma definitiva. Tampoco existe reportado un estudio de variabilidad morfológica, ni en estas ni en otras poblaciones de Sabal mexicana presentes en Nicaragua que permitiera comparar los dos tipos de marcadores. A pesar de las pocas muestras analizadas por procedencia, se logró determinar un alto nivel de polimorfismo presente en ellas, y una gran eficiencia de los marcadores RAPDs para detectarla. Pero para obtener resultados más concluyentes de la diversidad genética presente en las procedencias de Sabal mexicana, es necesario aumentar tanto el número de muestras por procedencia como el número de cebadores para obtener mayor cantidad de marcadores moleculares y poder realizar estimaciones de sus frecuencias génicas •

\section{Agradecimientos}

Los autores manifiestan su agradecimiento a la MSc. Rebeca Pastora y MSc. M. Inés Dávila por suministrar las semillas a través del proyecto Dinámica Ecológica del Bosque Seco y Fomento del Cultivo de la Palma Paceña (Sabal mexicana Mart) en el Occidente de Nicaragua. (MAGFOR-PROFOR, UNAN-León). Este trabajo fue apoyado por la Comunidad Autónoma de Madrid (CAM) y la Universidad de Alcalá de Henares en el marco de la Cooperación Española con la UNAN-León.

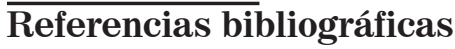

-ARMAS, R. y CANALES, M., (2003). Ecología y distribución de Sabal mexicana Mart en el Pacífico norte de Nicaragua, (2002-2003). Tesis de Licenciatura, León, UNAN-León. -BARTISH, I. et al., (2000). "Phylogenetic relationships and differentiation among and within populations of Chaenomeles Lind I. (Rosaceae) estimated with RAPDs and isozymes" Theor. 
Appl. Genet. Vol. 101: 554-563.

-BUSSELL, J. (1999). “The distribution of Random Amplified Polymorphic DNA (RAPD) diversity among populations of Isotoma petraea (Lobeliaceae)”. Mol. Ecol. Vol. 8: 775-789. -DÁVILA, M. (2003). Proyecto dinámica ecológica del bosque seco y fomento del cultivo de la palma paceña Sabal mexicana Mart., en el occidente de Nicaragua, PROFOR, UNANLEON, Subcomponente, variabilidad genética a nivel proteico, informe técnico. León-Nicaragua, UNAN-León.

-DAWSON, K. et al., (1995). "Diversity and genetic differentiation among subpopulations of Gliricidia sepium revealed by PCR-based assays”. Heredity, Vol.74. 10-18.

-DIAZ, M.; MUÑIZ, L. y FERRER, E. (2001). "Random amplified polymorphic DNA and amplified fragment length polymorphism assessment of genetic variation in Nicaraguan populations of Pinus oocarpa”. Mol. Ecol. Vol.10, 2593-2603.

-FONTAINE, C. et al., (2004). "Genetic diversity of the shea tree Vitellaria paradoxa C. (F. Gaertn), detected by RAPD and chloroplast microsatellite markers", Heredity, Vol. 93. 639-648.

-FRANKHAM, R.; BALLOU, J. y BRISCOE, D. (2002). Introduction to Conservation Genet$i c s$, Cambridge University Press, U.S.A.

-GONZÁLEZ, M. y SOSA, P., La Palmera Canaria (Phoenix canariensis): Diversidad Genética e Hibridación. Gran Canaria, España. (en línea). (2002). (Consultado 26 de enero 2005). Disponible en Internet: //www.gobcan.rs/medioambiente/revista/2002/23/-11k.

-HAMRICK, J. y GODT, M. (1989). Allozyme diversity in plant species. En: plant population genetics, breeding and genetic resources (Editado por A.H.D. Brown, M. T. Clegg, A.L. Kahler, B.S. Weir,), Sinauer Assoc Sunderland. Mass.

-HAMRICK, J. (1994). "Genetic diversity and conservation in tropical forest". In: Drysdale, R. M., John, S. E. T. and Yapa, A. C. (eds) Procedings of the international Symposium on Genetic Conservation and Production of Tropical ASEAN-Canada Forest Tree Seed Centre Proyect, Muak-Saraburi, Thailand. Fprest Tree Seed, pág 1-9.

-HOGBIN, P. y PEAKALL, R. (1999). "Evaluation of the Contribution of Genetic Research to the Management of the Endangered Plant Zieria prostrata”, Australian National University, Australia, Conservation Biology, 514-522.

-ISABEL, N. et al., (1999). "Direct evidence for biased gene diversity estimates from dominant Random Amplified Polymorphic DNA (RAPD) fingerprints”. Mol. Ecol. Vol 8. 477-483. -LOO, A. et al., (1999). "Population Analysis of Licuala glabra Griff. Var, glabra (Palmae) using RAPD Profiling", Annals of Botany, 421-427.

-MÖLLER, E. et al., (1992). "A simple and efficient protocol for isolation of high molecular weight DNA from filamentous fungi, fruit, bodies, and infected plant tissues", Nucleic Acid Research, Vol. 20. 6115-6116.

-NEBAUER, S. et al., (1999). "RAPD variation within and among natural populations of outcrossing willow-leaved foxglove (Digitalis obscura L.)". Theor. Appl. Genet. Vol. 98. 985994.

-NEI, M. (1987). Molecular evaluationary genetics, Columbia University Press, New York. -NYBOM, H. y BARTISH, I. (2000). "Effects of life history traits and sampling strategies on genetic diversity estimates obtained with RAPD markers in plants", Perspectives in Plant Ecology, Evolution and Systematics, Vol. 3/2. 93-114.

-RAMOS, M y QUEZADA, V. (1980). Reconocimiento sobre el estado actual de los palmares de la región II, INAFOR, Departamento de Dendrología, Managua, Nicaragua, pág 
33-77.

-ROHLF, F., (1993). NTSYS-pc: Numerical taxonomy and multivariate analysis system, Version 1.80. Exeter Software. New York.

-SOLIMAN, S., ALI, B. y MORSY, M., (2003). "Genetic comparisons of Egyptian date palm cultivars (Phoenix dactylifera L.) by RAPD-PCR”, African Journal of Biotechnology, Vol. 2(4), 86-87.

-WILLIAMS, G. et al., (1990). "DNA Polymorphisms amplified by arbitrary primers are useful as genetic markers”, Nucleic. Acids. Res. Vol. 18. 6521-6535. 